\title{
Adsorption Separation of Analgesic Pharmaceuticals from Ultrapure and Waste Water: Batch Studies Using a Polymeric Resin and an Activated Carbon
}

\author{
Ricardo N. Coimbra ${ }^{1}$ (D), Carla Escapa ${ }^{1}$ (D) and Marta Otero ${ }^{2, *(D)}$ \\ 1 Department of Applied Chemistry and Physics, Institute of Environment, Natural Resources and \\ Biodiversity (IMARENABIO), Universidad de León, 24001 León, Spain; \\ ricardo.decoimbra@unileon.es (R.N.C.); carla.escapa@unileon.es (C.E.) \\ 2 Centre for Environmental and Marine Studies (CESAM), Department of Environment and Planning, \\ University of Aveiro, 3800 Aveiro, Portugal \\ * Correspondence: marta.otero@ua.pt; Tel.: +351-234-247-094
}

Received: 23 July 2018; Accepted: 27 August 2018; Published: 29 August 2018

\begin{abstract}
The performance of a polymeric resin (Sepabeads SP207, from Resindion, Binasco, Italy) was compared with that of an activated carbon (GPP20, from Chemviron Carbon, Feluy, Belgium) in the adsorption of acetaminophen and ibuprofen from either ultrapure or waste water. Kinetic and equilibrium adsorption experiments were carried out under batch operation conditions, and fittings of the obtained results to different models were determined. The kinetic experimental results fitted the pseudo-first and -second order equations, and the corresponding kinetic rates evidenced that the pharmaceuticals adsorption was faster onto GPP20 than onto Sepabeads SP207, but was mostly unaffected by the aqueous matrix. The equilibrium results fitted the Langmuir-Freundlich isotherm model. The corresponding maximum adsorption capacity $\left(Q_{\mathrm{m}}, \mathrm{mg}^{-1}\right)$ was larger onto GPP20 $\left(202 \mathrm{mg} \mathrm{g}^{-1} \leq Q_{\mathrm{m}} \leq 273 \mathrm{mg} \mathrm{g}^{-1}\right)$ than onto the polymeric resin $\left(7 \mathrm{mg} \mathrm{g}^{-1} \leq Q_{\mathrm{m}} \leq 18 \mathrm{mg} \mathrm{g}^{-1}\right)$. With respect to the parameter $K_{\mathrm{LF}}\left(\mathrm{mg} \mathrm{g}^{-1}\left(\mathrm{mg} \mathrm{L}^{-1}\right)^{-1 / \mathrm{n}}\right)$, which points to the adsorbent-adsorbate affinity, greater values were determined for the pharmaceuticals adsorption onto GPP20 than onto Sepabeads SP207. For both adsorbents and pharmaceuticals, neither $Q_{\mathrm{m}}$ or $K_{\mathrm{LF}}$ were affected by the aqueous matrix.
\end{abstract}

Keywords: emerging contaminants; medicines; paracetamol; sewage; waste water treatment

\section{Introduction}

Emerging contaminants (ECs) may be defined as compounds that are not currently covered by existing water regulations but are thought to be a threat to environmental ecosystems and human health [1]. Amongst them, pharmaceuticals constitute a group of large concern, since they were designed to trigger a physiological response. Therefore, the presence of pharmaceuticals in the aquatic environment, even at relative low concentrations, may affect non-target individuals and species.

ECs may enter the environment by different routes, depending on their usage pattern and on their application mode. In the specific case of pharmaceuticals that come from human consumption and/or excretion, municipal waste water treatment plants (WWTPs) are main sources in the aquatic environment [1]. These plants are mostly inefficient in the removal of these pollutants since the primary and secondary treatments usually applied were not designed for this purpose, but for the removal of regulated parameters [2]. However, since legislation on the discharge of pharmaceuticals is expected to come out in the near future [3], it is necessary to find efficient treatments.

Removal of pharmaceuticals at WWTPs before discharge would be possible by the inclusion of an appropriate tertiary treatment [4]. Among the different options, adsorptive treatments are convenient 
due to their low energy consumption and simple operation [5]. Furthermore, the incorporation of adsorptive treatments into current WWTPs is quite feasible [6]. Recently, Akhtar et al. [7] reviewed the literature on the adsorption and adsorbents used for the removal of pharmaceuticals from water. Although activated carbon is the most frequently used adsorbent for this purpose [8], polymeric materials have been also employed in such applications [9-14]. Polymeric adsorbents have several advantages over conventional activated carbons: their simpler processing; considerably easier regeneration; the possibility to shape them into the most suitable form (e.g., sheets, beads, membranes); the potential of controlling the pore structure and internal surface area by varying the polymerization conditions [15]; and the possible modification of their physical and chemical properties [16]. In any case, and whatever the adsorbent, a main advantage of adsorption processes for the removal of pharmaceuticals from water is that they do not entail the generation of transformation products [17-19], whose concentration and/or toxicity may be larger than for the parent compound.

Anti-inflamatory drugs are frequently detected in natural waters due to their widespread consumption [20]. In fact, acetaminophen and ibuprofen are among the most widely used drugs for fever and headaches, since they may be acquired without prescription. Due to their over-the-counter availability, they are mostly ubiquitous in municipal waste water, with high detection frequencies and relatively high concentrations compared with other drugs [21]. Indeed, in a recent work by Bellver-Domingo et al. [22], the shadow price for the WWTPs discharge of several ECs was evaluated in three ecosystems, namely wetlands, river, and sea. The aim was to weigh the environmental damage caused by ECs, which is essential information to frame the subsequent decision-making process on the management measures that should be implemented. These authors [22] found that, for the three ecosystems, acetaminophen, followed by ibuprofen, had the largest shadow prices among the studied ECs, which points to the removal of these pharmaceuticals from WWTPs effluents as a priority.

Several authors have reported the utilization of different types of adsorbents to remove acetaminophen [23-25] and ibuprofen [26-28] from water. However, just Suntisukaseam et al. [29] studied the utilization of three polymeric resins (Amberlite XAD2, XAD7, and XAD761) for the adsorption of acetaminophen from ultrapure water. Still, to our best knowledge, the utilization of polymeric resins for the adsorptive separation of acetaminophen and ibuprofen from waste water has never been assessed. In fact, the scarceness of studies on the adsorptive removal of pharmaceuticals from such a matrix (waste water) versus a majority of published results from experiments carried out in deionized or ultrapure water was recently highlighted [30].

In this context, the aim of the present work was to compare the performance of a polymeric resin and an activated carbon in the removal of two pain relievers, viz. acetaminophen and ibuprofen, both with large global consumption and occurrence in waste water. In view of the practical application of these adsorbents in the tertiary treatment of waste water, the adsorption of the considered pharmaceuticals was studied both from ultrapure water and from the secondary effluent of a municipal WWTP.

\section{Materials and Methods}

\subsection{Adsorbent Materials}

The activated carbon used in this study was pulverised GPP20, which was kindly provided by Chemviron Carbon (Feluy, Belgium). The utilization of GPP20 was recommended by Chemviron Carbon for the adsorption of pharmaceuticals, since it is an activated carbon suitable for waste water treatment applications, namely, for the removal of aromatic compounds. The polymeric resin Sepabeads SP207 (Mitsubishi Chemical Corp., Tokyo, Japan) was gently offered by Resindion (Binasco, Italy). Resindion pointed to Sepabeads SP207 as an appropriate solution for the adsorption of aromatic compounds, including pharmaceuticals. On the other hand, according to the manufacturer (Mitsubishi Chemical Corp., Tokyo, Japan), and due to its high specific gravity, this resin is appropriate not only for fixed-bed, but also for batch adsorption operation. The adsorbent materials here used 
were selected for this work because they have already been used for the removal of pharmaceuticals and/or other organic pollutants from water (including waste water) $[9,10,31,32]$. Table 1 shows the physical characteristics of these adsorbents.

Table 1. Physical properties of adsorbents used for diclofenac acid adsorption.

\begin{tabular}{ccc}
\hline Adsorbent & GPP20 & Sepabeads SP207 \\
\hline Matrix & Coal based steam activated carbon & Styrene-divinylbenzene copolymer \\
Colour & Black carbon & Yellowish opaque beads \\
Specific surface area $\left(\mathrm{m}^{2} \mathrm{~g}^{-1}\right)$ & 1000 & 650 \\
Mean particle diameter $(\mathrm{mm})$ & 0.04 & 0.4 \\
\hline
\end{tabular}

\subsection{Chemicals and Analytic Methods}

Acetaminophen $(\geq 99 \%)$ was purchased from Sigma-Aldrich (Steinheim, Germany), while ibuprofen sodium ( $\geq 98 \%$ ) was purchased from Fluka (Buchs, Switzerland). The main properties of these pharmaceuticals are depicted in Table 2.

Table 2. Physico-chemical properties of the pharmaceuticals used in this study (Source: Chemspider and Chemicalize).

\begin{tabular}{|c|c|c|c|c|c|c|c|}
\hline $\begin{array}{l}\text { Pharmaceutical } \\
\text { (Formula) }\end{array}$ & Structure & $\mathrm{Mw}\left(\mathrm{g} \mathrm{mol}^{-1}\right)$ & $\mathrm{Sw}^{\mathrm{a}}\left(\mathrm{mg} \mathrm{L}^{-1}\right)$ & pKa & $\log K_{o w}$ & $\operatorname{PSA}\left(\mathrm{A}^{2}\right)$ & HBAC \\
\hline $\begin{array}{l}\text { Ibuprofen Sodium } \\
\qquad\left(\mathrm{C}_{3} \mathrm{H}_{17} \mathrm{NaO}_{2}\right)\end{array}$ & & 228.26 & 100,000 & 4.91 & 3.8 & 40.1 & 2 \\
\hline $\begin{array}{c}\text { Acetaminophen } \\
\left(\mathrm{C}_{8} \mathrm{H}_{9} \mathrm{NO}_{2}\right)\end{array}$ & & 151.17 & 14,000 & 9.48 & 0.46 & 49.3 & 2 \\
\hline
\end{tabular}

PSA $=$ Polar Surface Area, HBAC $=$ Hydrogen Bound Acceptor Count,${ }^{\text {a }} \mathrm{Sw}=$ water solubility $\left(25^{\circ} \mathrm{C}\right)$.

The target pharmaceuticals were analysed by High Performance Liquid Chromatography (HPLC), using a Waters HPLC 600 equipped with a 2487 Dual $\lambda$ Absorbance Detector, a phenomenex C18 column $(5 \mu \mathrm{m}, 110 \AA, 250 \times 4.6 \mathrm{~mm})$, a Rheodyne injector and a $50 \mu \mathrm{L}$ loop. The wavelengths of detection were 246 and 220 for acetaminophen and ibuprofen, respectively. The mobile phase consisted of a mixture of acetonitrile:water $(30: 70, v / v)$ for the analysis of acetaminophen and a mixture of methanol:water:orthophosphoric acid (75:25:0.3) for the analysis of ibuprofen. For the preparation of the mobile phase mixtures, HPLC quality acetonitrile $\left(\mathrm{CH}_{3} \mathrm{CN}\right)$ and methanol $\left(\mathrm{CH}_{3} \mathrm{OH}\right)$ were acquired from Sigma-Aldrich (Madrid, Spain), orthophosphoric acid $\left(\mathrm{H}_{3} \mathrm{PO}_{4}\right)$ was purchased from Panreac (Barcelona, Spain), and ultrapure water obtained by a Milli-Q purification system from Merck Millipore (Darmstadt, Germany). Before use, each mixture was passed through a Millipore $0.45 \mu \mathrm{m}$ pore size filter and degasified in an ultrasound bath for $30 \mathrm{~min}$. For the chromatographic determination of concentration, four replicated injections were carried out under a mobile phase flow rate of $1 \mathrm{~mL} \mathrm{~min}{ }^{-1}$.

\subsection{Aqueous Matrices for Adsorption Experiments}

In this work, adsorption experiments were first carried out in ultrapure water (conductivity $=55 \mu \mathrm{S} \cdot \mathrm{cm}^{-1}$, resistivity $=18.18 \mathrm{M} \Omega . \mathrm{cm}$ and $\mathrm{pH}=6.9$ at $25^{\circ} \mathrm{C}$ ), which was sourced by a Milli-Q purification system. Then, aiming to assess the possible utilisation of the considered adsorbents in tertiary waste water treatment, experiments on the adsorption of pharmaceuticals from real waste water were carried out. For this purpose, the secondary effluent from the municipal waste water treatment plant (WWTP) of León (Spain) was collected. This WWTP consists of a primary stage, followed by a secondary stage treatment. The primary stage comprises screening, sand removal, 
fat removal, and primary clarification treatments. Then, the secondary stage involves a plug-flow activated sludge with nitrification/denitrification followed by a secondary clarification. After the secondary clarification, the effluent is directly discharged at the Bernesga river, which has a length of $77 \mathrm{~km}$, and is a tributary of the Esla river. The WWTP was designed to treat the waste water of 330,000 equivalent inhabitants, and has an inflow of $123,000 \mathrm{~m}^{3}$ day $^{-1}$, with a hydraulic retention time (HRT) of about $6 \mathrm{~h}$.

Waste water quality parameters, namely $\mathrm{pH}$, conductivity, total suspended solids (TSS), biological oxygen demand at five days ( $\mathrm{BOD}_{5}$ ), chemical oxygen demand (DQO), $\mathrm{NTK}, \mathrm{N}-\mathrm{NH}_{4}, \mathrm{~N}-\mathrm{NO}_{3}, \mathrm{~N}-\mathrm{NO}_{2}$, total $\mathrm{P}-\mathrm{PO}_{4}$, were determined according to Standard Methods [33]. The determined parameters are shown in Table 3, together with European regulations on the discharge of this sort of effluents, which, as may be seen, are fulfilled.

Table 3. Main properties of the urban WWTP effluent used in this work.

\begin{tabular}{|c|c|c|c|c|c|c|c|c|c|}
\hline \multirow{2}{*}{$\mathrm{pH}$} & Conductivity & TSS & BOD $_{5}$ & COD & NTK & $\mathrm{N}-\mathrm{NH}_{4}$ & $\mathrm{~N}-\mathrm{NO}_{3}$ & $\mathrm{~N}-\mathrm{NO}_{2}$ & Total ${\mathrm{P}-\mathrm{PO}_{4}}_{4}$ \\
\hline & $\left(\mu \mathrm{S} \mathrm{cm}^{-1}\right)$ & $\left(\mathrm{mg} \mathrm{L}^{-1}\right)$ & $\left(\mathrm{mg} \mathrm{L}^{-1}\right)$ & $\left(\mathrm{mg} \mathrm{L}^{-1}\right)$ & $\left(\mathrm{mg} \mathrm{L}^{-1}\right)$ & $\left(\mathrm{mg} \mathrm{L}^{-1}\right)$ & $\left(\mathrm{mg} \mathrm{L}^{-1}\right)$ & $\left(\mathrm{mg} \mathrm{L}^{-1}\right)$ & $\left(\mathrm{mg} \mathrm{L}^{-1}\right)$ \\
\hline $7.8 \pm 0.2$ & $612 \pm 3$ & $\begin{array}{c}22 \pm 1 \\
35^{*}\end{array}$ & $\begin{array}{c}21 \pm 2 \\
25^{*}\end{array}$ & $\begin{array}{c}47 \pm 3 \\
125^{*}\end{array}$ & $17 \pm 2$ & $13.10 \pm 0.42$ & $1.73 \pm 0.18$ & $0.48 \pm 0.09$ & $1.75 \pm 0.13$ \\
\hline
\end{tabular}

* Limits for discharge according to the Urban Waste Water Directive (Council Directive 91/271/EEC of 21 May 1991 concerning urban waste water treatment as amended by Commission Directive 98/15/EC and Regulations 1882/2003/EC and $1137 / 2008 / \mathrm{EC})$.

\subsection{Adsorption Experiments}

Adsorption experiments were done under batch operation conditions. For each pharmaceutical, adsorption kinetic experiments were first carried out in order to determine the time necessary to attain equilibria $\left(t_{\mathrm{eq}}\right)$. Next, equilibrium experiments were done to determine the corresponding adsorption isotherm. All experiments were carried out by shaking ( $250 \mathrm{rpm})$ a known mass of adsorbent (Sepabeads SP207 or GPP20) together with $100 \mathrm{~mL}$ of ultrapure or waste water in $250 \mathrm{~mL}$ Erlenmeyer flasks. Initial concentration of each target pharmaceutical in waste water was $100 \pm 1 \mathrm{mg} \mathrm{L}^{-1}$. All experiments were done in triplicate and at a constant temperature of $25 \pm 2{ }^{\circ} \mathrm{C}$, provided by a thermostatically regulated shaker. Triplicate controls, which consisted of solutions of the corresponding pharmaceutical $\left(100 \pm 1 \mathrm{mg} \mathrm{L}^{-1}\right)$ in the absence of adsorbent, were run in parallel with adsorption experiments.

In the kinetic experiments, Erlenmeyer flasks were progressively withdrawn from the shaker after pre-set time intervals. Then, from each flask, three aliquots were taken, filtered, and chromatographically analyzed to determine the concentration of the target pharmaceutical. For each of the pharmaceuticals here considered (acetaminophen and ibuprofen), the adsorbed concentration onto each adsorbent at any time, $q_{\mathrm{t}}\left(\mathrm{mg} \mathrm{g}^{-1}\right)$, was calculated by the following mass balance relationship (Equation (1)):

$$
q_{\mathrm{t}}=\left(C_{0}-C_{\mathrm{t}}\right) \frac{V}{W}
$$

where $C_{\mathrm{t}}\left(\mathrm{mg} \mathrm{L}^{-1}\right)$ is the experimental liquid-phase concentration of pharmaceutical at a time $\mathrm{t}$, $C_{0}\left(\mathrm{mg} \mathrm{L}^{-1}\right)$ is the average concentration of pharmaceutical in the corresponding control, $V$ is the volume of the solution $(\mathrm{L})$, and $W$ is the mass $(\mathrm{g})$ of adsorbent.

For equilibrium experiments, Erlenmeyer flasks containing the target pharmaceutical solution together with the corresponding adsorbent were under shaking during the $t_{\text {eq. }}$. Then, from each flask, three aliquots were withdrawn, filtered and chromatographically analyzed to determine the pharmaceutical equilibrium concentration $\left(C_{\mathrm{e}}, \mathrm{mg} \mathrm{L}^{-1}\right)$ in the liquid phase. Then, the equilibrium adsorbed concentration of pharmaceutical onto the corresponding adsorbent, $q_{\mathrm{e}}\left(\mathrm{mg} \mathrm{g}^{-1}\right)$, was calculated by the mass balance relationship displayed in Equation (2):

$$
q_{\mathrm{e}}=\left(C_{0}-C_{\mathrm{e}}\right) \frac{V}{W}
$$


where $C_{\mathrm{e}}\left(\mathrm{mg} \mathrm{L}^{-1}\right)$ is the experimental equilibrium liquid-phase concentration of pharmaceutical.

\subsection{Modeling of Adsorption Results}

Fittings of the obtained kinetic results to the pseudo first-order [34] and the pseudo second-order [35] equations, which are next shown (Equations (3) and (4), respectively), were determined.

$$
\begin{gathered}
q_{\mathrm{t}}=q_{\mathrm{e}}\left(1-\mathrm{e}^{-k_{1} \mathrm{t}}\right) \\
q_{\mathrm{t}}=\frac{q_{\mathrm{e}}^{2} k_{2} \mathrm{t}}{1+q_{\mathrm{e}} k_{2} \mathrm{t}}
\end{gathered}
$$

where $k_{1}\left(\min ^{-1}\right)$ and $k_{2}\left(\mathrm{mg} \mathrm{g}^{-1} \mathrm{~min}\right)$ are the pseudo-first and the pseudo-second order rate constants, respectively.

Fittings of the obtained adsorption equilibrium results to three different isotherm models were determined, namely the Freundlich isotherm [36], the Langmuir isotherm [37] and the Sips isotherm [38], which is commonly designated as the Langmuir-Freundlich isotherm. These isotherms are next depicted by Equations (5), (6) and (7), respectively.

$$
\begin{gathered}
q_{\mathrm{e}}=K_{\mathrm{F}} C_{\mathrm{e}}^{1 / \mathrm{n}} \\
q_{\mathrm{e}}=\frac{Q_{\mathrm{m}} K_{\mathrm{L}} C_{\mathrm{e}}}{1+K_{\mathrm{L}} C_{\mathrm{e}}} \\
q_{\mathrm{e}}=\frac{Q_{\mathrm{m}} K_{\mathrm{LF}} C_{\mathrm{e}}^{\frac{1}{n}}}{1+K_{\mathrm{LF}} C_{\mathrm{e}}^{\frac{1}{n}}}
\end{gathered}
$$

where $K_{\mathrm{F}}$ is the Freundlich adsorption constant $\left(\mathrm{mg} \mathrm{g}^{-1}\left(\mathrm{mg} \mathrm{L}^{-1-1 / n}\right) ; n\right.$ the degree of non-linearity; $Q_{m}$ the maximum adsorption capacity $\left(\mathrm{mg} \mathrm{g}^{-1}\right) ; K_{\mathrm{L}}\left(\mathrm{L} \mathrm{mg}^{-1}\right)$ and $K_{\mathrm{LF}}\left(\mathrm{mg} \mathrm{g}^{-1}\left(\mathrm{mg} \mathrm{L}^{-1}\right)^{-1 / \mathrm{n}}\right)$ are the Langmuir and Langmuir-Freundlich affinity coefficients, respectively.

\section{Results and Discussion}

The kinetic experimental results on the adsorption of acetaminophen and ibuprofen from ultrapure water onto the activated carbon (GPP20) and onto the polymeric resin (Sepabeads SP207) are represented in Figures 1 and 2. Meanwhile, Figures 3 and 4 represent the corresponding experimental kinetic results from waste water. In these figures, fittings to the kinetic models here considered (Equations (3) and (4)) are shown together with experimental results whereas the corresponding fitted parameters are depicted in Table 4. In Figures $1-4$, it is evidenced that $q_{\mathrm{t}}$ increases with $t$ until reaching the equilibrium, and then $q_{\mathrm{t}}$ remains stable throughout time. As it may be seen in these figures, although experimental results were slightly better described by the pseudo-second equation, both the here used kinetic models may be considered appropriate, which is confirmed by the $R^{2}\left(R^{2} \geq 0.98\right)$. As for the corresponding fitted kinetic constants in Table 4, the adsorption of the here studied pharmaceuticals was faster onto the activated carbon than onto the polymeric resin, which must be mainly related to the larger particle size of the latter (Table 1). On the other hand, the adsorption velocity was mostly unaffected by the matrix, with similar kinetic constants for the adsorption from ultrapure and waste water. Then, for the subsequent equilibrium experiments, the $t_{\mathrm{eq}}$ values for the adsorption onto GPP20 and onto Sepabeads SP207 were 48 and $72 \mathrm{~h}$, respectively. 
Table 4. Kinetic parameters obtained from the fittings of experimental results on the adsorption of acetaminophen and ibuprofen from ultrapure water (UPW) and from waste water (WW) to the pseudo-first and to the pseudo-second order equations.

\begin{tabular}{|c|c|c|c|c|c|c|c|c|c|}
\hline & \multirow{3}{*}{ Parameters } & \multicolumn{4}{|c|}{ Acetaminophen } & \multicolumn{4}{|c|}{ Ibuprofen } \\
\hline & & \multicolumn{2}{|c|}{ GPP20 } & \multicolumn{2}{|c|}{ SP207 } & \multicolumn{2}{|c|}{ GPP20 } & \multicolumn{2}{|c|}{ SP207 } \\
\hline & & UPW & WW & UPW & WW & UPW & WW & UPW & WW \\
\hline 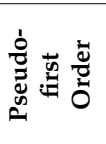 & $\begin{array}{c}k_{1}\left(\min ^{-1}\right) \\
q_{\mathrm{e}}\left(\mathrm{mg} \mathrm{g}^{-1}\right) \\
R^{2} \\
S_{x y}\end{array}$ & $\begin{array}{c}0.0098 \pm 0.0007 \\
180.60 \pm 2.48 \\
0.9914 \\
6.59\end{array}$ & $\begin{array}{c}0.0093 \pm 0.0006 \\
198.20 \pm 2.56 \\
0.9925 \\
6.76\end{array}$ & $\begin{array}{c}0.0021 \pm 0.0002 \\
3.95 \pm 0.09 \\
0.9800 \\
0.22\end{array}$ & $\begin{array}{c}0.0019 \pm 0.0002 \\
5.39 \pm 0.11 \\
0.9832 \\
0.27\end{array}$ & $\begin{array}{c}0.0105 \pm 0.0009 \\
99.95 \pm 1.63 \\
0.9872 \\
4.35\end{array}$ & $\begin{array}{c}0.0058 \pm 0.0004 \\
136.60 \pm 2.04 \\
0.9914 \\
5.04\end{array}$ & $\begin{array}{c}0.0016 \pm 0.00001 \\
15.24 \pm 0.27 \\
0.9889 \\
0.63\end{array}$ & $\begin{array}{c}0.0033 \pm 0.0003 \\
15.63 \pm 0.23 \\
0.9849 \\
0.73\end{array}$ \\
\hline 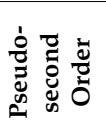 & $\begin{array}{c}k_{2}\left(\mathrm{~g} \mathrm{mg}^{-1} \mathrm{~min}^{-1}\right) \\
q_{\mathrm{e}}\left(\mathrm{mg} \mathrm{g} \mathrm{g}^{-1}\right) \\
R^{2} \\
S_{\mathrm{xy}}\end{array}$ & $\begin{array}{c}0.00008 \pm 0.00001 \\
191.20 \pm 2.99 \\
0.9916 \\
6.48\end{array}$ & $\begin{array}{c}0.00006 \pm 0.00001 \\
210.30 \pm 3.40 \\
0.9913 \\
7.30\end{array}$ & $\begin{array}{c}0.00069 \pm 0.00005 \\
4.34 \pm 0.05 \\
0.9961 \\
0.10\end{array}$ & $\begin{array}{c}0.00045 \pm 0.00003 \\
5.96 \pm 0.08 \\
0.9958 \\
0.13\end{array}$ & $\begin{array}{c}0.00015 \pm 0.00001 \\
105.60 \pm 1.49 \\
0.9926 \\
3.29\end{array}$ & $\begin{array}{c}0.00006 \pm 0.000004 \\
146.90 \pm 1.75 \\
0.9961 \\
3.39\end{array}$ & $\begin{array}{c}0.00013 \pm 0.00001 \\
17.04 \pm 0.32 \\
0.9927 \\
0.51\end{array}$ & $\begin{array}{c}0.00031 \pm 0.00003 \\
16.77 \pm 0.27 \\
0.9911 \\
0.55\end{array}$ \\
\hline
\end{tabular}


(a)

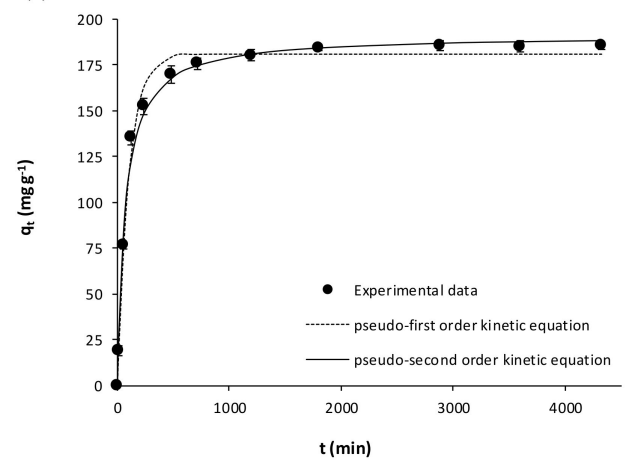

(b)

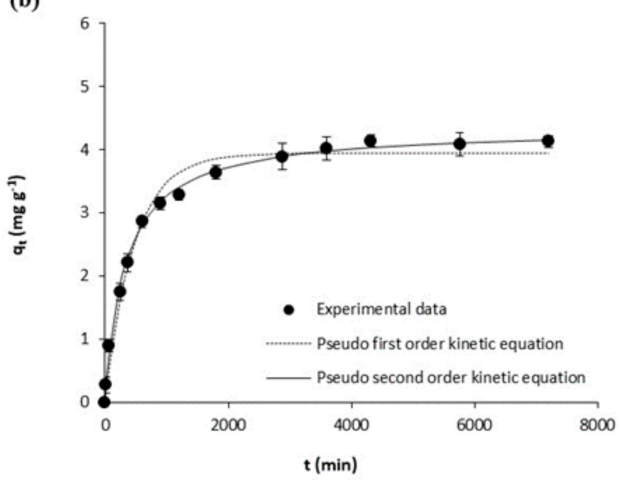

Figure 1. Kinetic results on the adsorptive removal of acetaminophen from ultrapure water by adsorption onto (a) the activated carbon GPP20 and (b) the polymeric resin Sepabeads SP207. Experimental results are shown together with fittings to the pseudo-first and pseudo second order kinetic equations. Error bars stand for standard deviation of three experimental replications. Note: for a better visualization of fittings, the scale of axis $\mathrm{Y}$ has been adjusted to results.

(a)

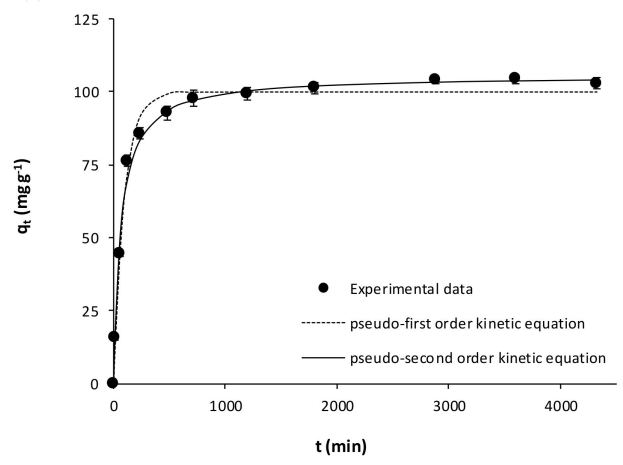

(b)

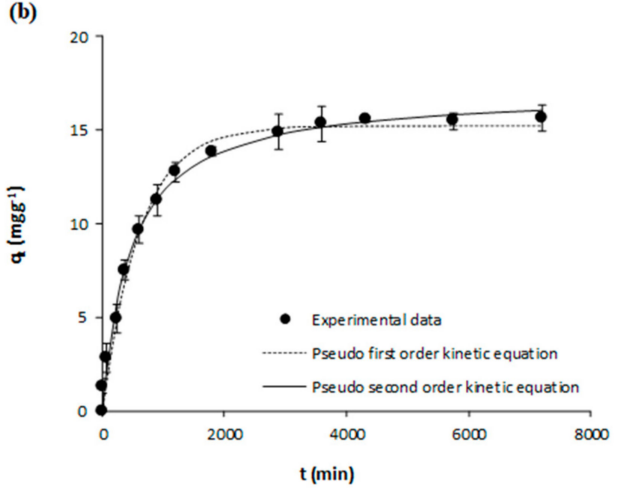

Figure 2. Kinetic results on the adsorptive removal of ibuprofen from ultrapure water by adsorption onto (a) the activated carbon GPP20 and (b) the polymeric resin Sepabeads SP207. Experimental results are shown together with fittings to the pseudo-first and pseudo second order kinetic equations. Error bars stand for standard deviation of three experimental replications. Note: for a better visualization of fittings, the scale of axis $\mathrm{Y}$ has been adjusted to results.

(a)

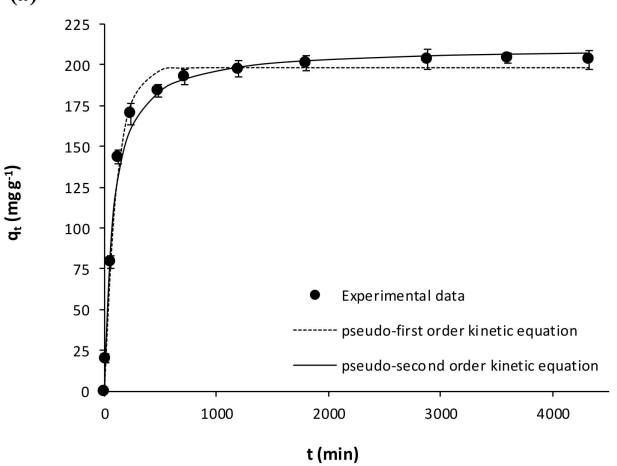

(b)

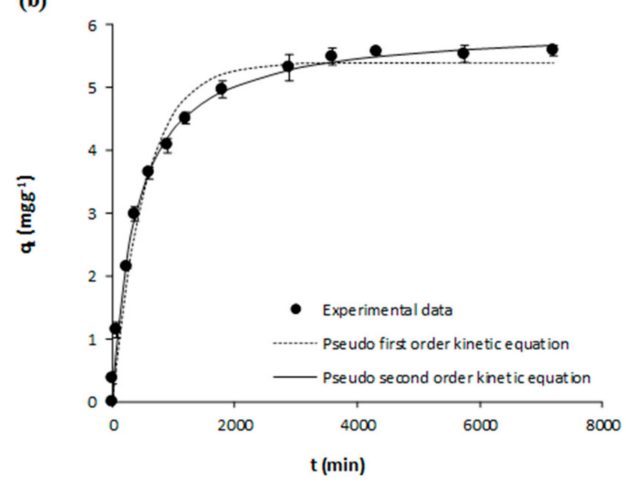

Figure 3. Kinetic results on the adsorptive removal of acetaminophen from waste water by adsorption onto (a) the activated carbon GPP20 and (b) the polymeric resin Sepabeads SP207. Experimental results are shown together with fittings to the pseudo-first and pseudo second order kinetic equations. Error bars stand for standard deviation of three experimental replications. Note: for a better visualization of fittings, the scale of axis $\mathrm{Y}$ has been adjusted to results. 
(a)

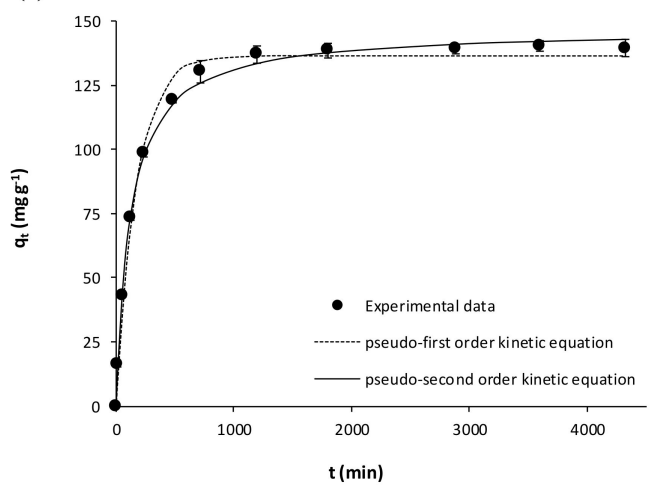

(b)

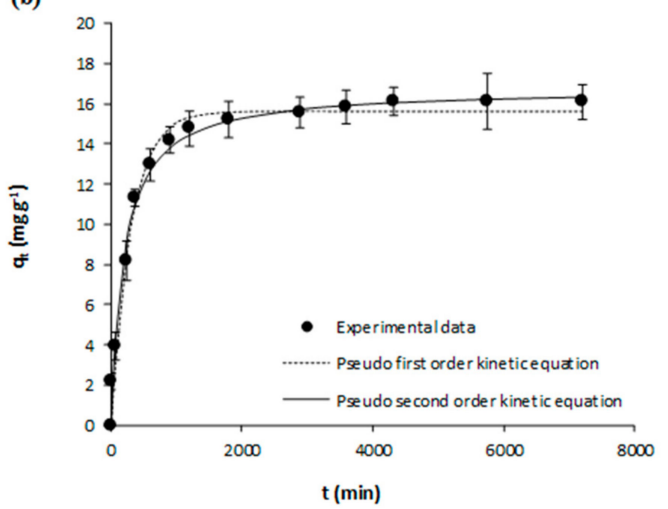

Figure 4. Kinetic results on the adsorptive removal of ibuprofen from waste water by adsorption onto (a) the activated carbon GPP20 and (b) the polymeric resin Sepabeads SP207. Experimental results are shown together with fittings to the pseudo-first and pseudo second order kinetic equations. Error bars stand for standard deviation of three experimental replications. Note: for a better visualization of fittings, the scale of axis $\mathrm{Y}$ has been adjusted to results.

The equilibrium experimental results on the adsorption of acetaminophen and ibuprofen from ultrapure water are shown in Figures 5 and 6, respectively. Those on the adsorption of acetaminophen and ibuprofen from waste water are respectively depicted in Figures 7 and 8. Equilibrium data are represented in these figures, together with fittings to the considered isotherm models (Equations (5)-(7)); the corresponding fitted parameters are depicted in Table 5.
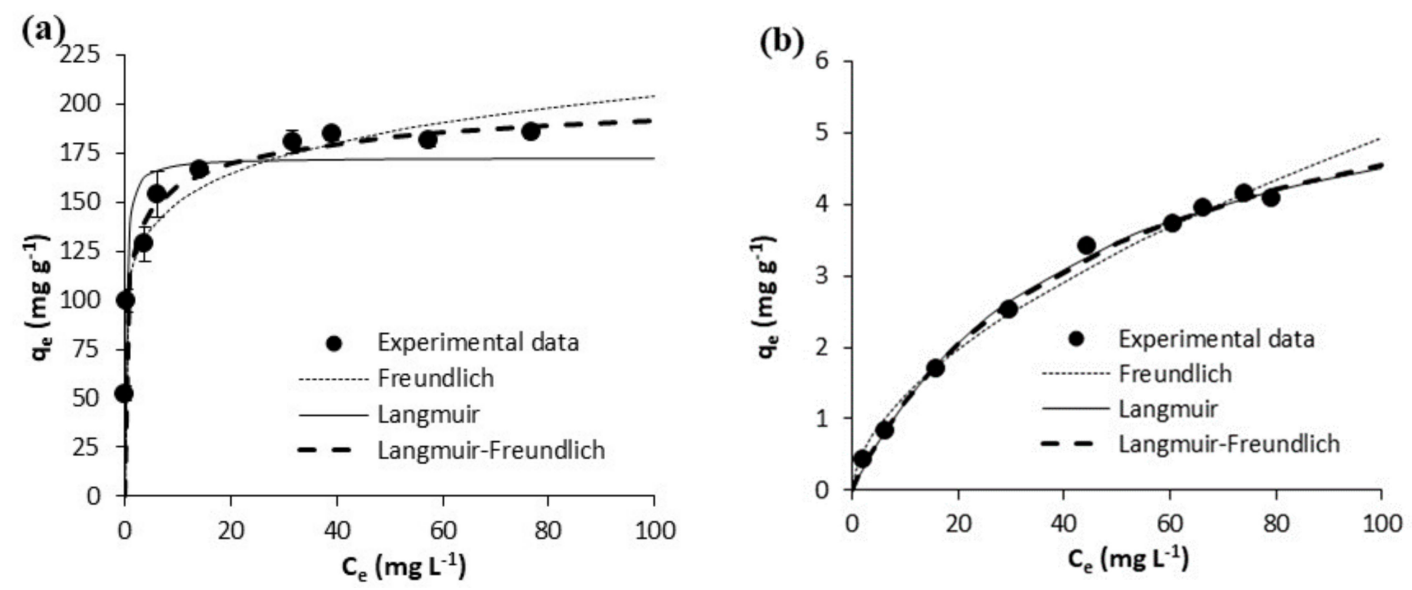

Figure 5. Equilibrium results on the adsorptive removal of acetaminophen from ultrapure water by adsorption onto (a) the activated carbon GPP20 and (b) the polymeric resin Sepabeads SP207. Experimental results are shown together with fittings to the Freundlich, to the Langmuir and to the Langmuir-Freundlich isotherm models. Error bars stand for the standard deviation of three experimental replications. Note: for a better visualization of fittings, the scale of axis $Y$ has been adjusted to results. 
Table 5. Isotherm parameters obtained from the fittings of the equilibrium experimental results on the adsorption of acetaminophen and ibuprofen from ultrapure water (UPW) and from waste water (WW) to the isotherm models of Freundlich, Langmuir and Langmuir-Freundlich.

\begin{tabular}{|c|c|c|c|c|c|c|c|c|c|}
\hline & \multirow{3}{*}{ Parameters } & \multicolumn{4}{|c|}{ Acetaminophen } & \multicolumn{4}{|c|}{ Ibuprofen } \\
\hline & & \multicolumn{2}{|c|}{ GPP20 } & \multicolumn{2}{|c|}{ SP207 } & \multicolumn{2}{|c|}{ GPP20 } & \multicolumn{2}{|c|}{ SP207 } \\
\hline & & UPW & WW & UPW & WW & UPW & WW & UPW & WW \\
\hline \multirow{4}{*}{ 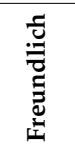 } & $K_{\mathrm{F}}\left[\mathrm{mg} \mathrm{g}^{-1}\left(\mathrm{mg} \mathrm{L}^{-1}\right)^{-1 / \mathrm{n}}\right]$ & $110.10 \pm 5.42$ & $108.60 \pm 10.44$ & $0.36 \pm 0.06$ & $0.47 \pm 0.16$ & $55.30 \pm 1.51$ & $78.39 \pm 2.88$ & $2.60 \pm 0.65$ & $2.97 \pm 0.54$ \\
\hline & $N$ & $7.45 \pm 0.81$ & $6.27 \pm 1.12$ & $1.75 \pm 0.12$ & $1.79 \pm 0.27$ & $6.78 \pm 0.36$ & $6.80 \pm 0.49$ & $2.27 \pm 0.35$ & $2.51 \pm 0.30$ \\
\hline & $R^{2}$ & 0.9519 & 0.8761 & 0.9878 & 0.947 & 0.9865 & 0.9788 & 0.9342 & 0.9491 \\
\hline & $S_{\mathrm{y} x}$ & 10.85 & 24.97 & 0.1704 & 0.41 & 3.19 & 6.16 & 1.52 & 1.45 \\
\hline \multirow{4}{*}{ 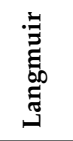 } & $Q_{\mathrm{m}}\left(\mathrm{mg} \mathrm{g}^{-1}\right)$ & $172.40 \pm 8.34$ & $191.20 \pm 5.81$ & $6.43 \pm 0.28$ & $8.25 \pm 1.01$ & $92.26 \pm 5.60$ & $131.40 \pm 9.66$ & $20.33 \pm 1.16$ & $18.17 \pm 0.75$ \\
\hline & $K_{\mathrm{L}}\left(\mathrm{L} \mathrm{mg}^{-1}\right)$ & $4.181 \pm 2.019$ & $3.688 \pm 0.545$ & $0.023 \pm 0.002$ & $0.023 \pm 0.006$ & $3.273 \pm 1.447$ & $3.144 \pm 1.448$ & $0.054 \pm 0.009$ & $0.088 \pm 0.006$ \\
\hline & $R^{2}$ & 0.8285 & 0.9772 & 0.9964 & 0.9714 & 0.7751 & 0.7729 & 0.857 & 0.9967 \\
\hline & $s_{\mathrm{yx}}$ & 20.47 & 10.72 & 0.09326 & 0.30 & 13.00 & 20.16 & 0.70 & 0.37 \\
\hline \multirow{5}{*}{ 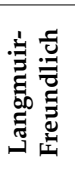 } & $Q_{\mathrm{m}}\left(\mathrm{mg} \mathrm{g}^{-1}\right)$ & $235.00 \pm 26.83$ & $201.70 \pm 7.49$ & $6.90 \pm 1.12$ & $6.53 \pm 1.26$ & $260.10 \pm 108.70$ & $272.90 \pm 133.30$ & $17.25 \pm 1.13$ & $17.82 \pm 0.68$ \\
\hline & $K_{\mathrm{LF}}\left[\mathrm{mg} \mathrm{g}^{-1}\left(\mathrm{mg} \mathrm{L}^{-1}\right)^{-1 / n}\right]$ & $0.954 \pm 0.254$ & $2.055 \pm 0.471$ & $0.025 \pm 0.004$ & $0.073 \pm 0.010$ & $0.273 \pm 0.283$ & $0.414 \pm 0.298$ & $0.026 \pm 0.011$ & $0.084 \pm 0.040$ \\
\hline & $N$ & $2.99 \pm 0.52$ & $1.39 \pm 0.19$ & $1.06 \pm 0.12$ & $0.76 \pm 0.22$ & $4.88 \pm 1.55$ & $4.23 \pm 1.527$ & $0.71 \pm 0.11$ & $0.96 \pm 0.070$ \\
\hline & $R^{2}$ & 0.9852 & 0.9890 & 0.9965 & 0.9760 & 0.9880 & 0.9844 & 0.9920 & 0.9968 \\
\hline & $S_{\mathrm{yx}}$ & 6.49 & 8.15 & 0.10 & 0.31 & 3.24 & 5.80 & 0.58 & 0.39 \\
\hline
\end{tabular}



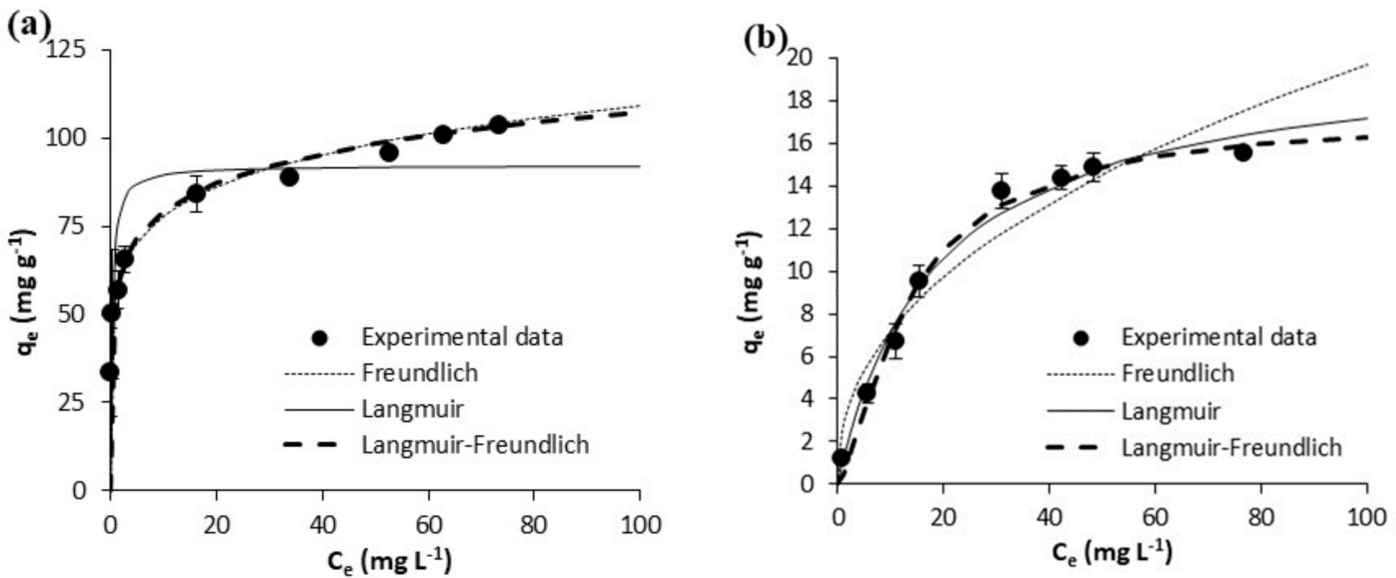

Figure 6. Equilibrium results on the adsorptive removal of ibuprofen from ultrapure water by adsorption onto (a) the activated carbon GPP20 and (b) the polymeric resin Sepabeads SP207. Experimental results are shown together with fittings to the Freundlich, to the Langmuir and to the Langmuir-Freundlich isotherm models. Error bars stand for the standard deviation of three experimental replications. Note: for a better visualization of fittings, the scale of axis $\mathrm{Y}$ has been adjusted to results.

As may be seen in Figure 5, from ultrapure water, the adsorbed concentrations of acetaminophen at the equilibrium were larger onto GPP20 than onto Sepabeads SP207, which must be largely due to the greater specific surface area of the first (Table 1). In agreement, larger adsorption concentrations at the equilibrium were also determined for ibuprofen onto GPP20 than onto the polymeric resin.

When comparing the adsorption of acetaminophen and ibuprofen, larger $q_{\mathrm{e}}$ were determined for acetaminophen than for ibuprofen onto the activated carbon GPP20, while the opposite was observed in the case of Sepabeads SP207. Since $\mathrm{pH}$ effects strongly affect the adsorption process in general and the adsorption capacity in particular, this difference must be related to the different $\mathrm{pKa}$ values of the pharmaceuticals (Table 2). According to these values, acetaminophen is neutral at the $\mathrm{pH}$ of ultrapure water $(\mathrm{pH}=6.9)$, while ibuprofen is negatively charged. Therefore, in the case of acetaminophen, the main factor conditioning its binding is the occurrence of non-electrostatic interactions such as hydrogen-bonds and Van deer Waals-forces. Differently, the adsorption of ibuprofen is affected by electrostatic interactions. In fact, the point of zero charge (PZC) of GPP20 and Sepabeads SP207 were determined to be 7.4 and 8.6, respectively. Hence, while the surface of GPP20 at the working pH is mostly uncharged, that of the polymeric resin is positively charged, which explains its higher affinity and capacity for ibuprofen (negative charged form) than for acetaminophen (neutral form).

In waste waster (Figures 7 and 8), the adsorption equilibrium isotherms remained mostly the same as those in ultrapure water, with the above observations being also applicable. Yet, at the $\mathrm{pH}$ of waste water (7.8), acetaminophen and ibuprofen are neutral and negatively charged, respectively. On the other hand, the surface of the GPP20 is mostly neutral, and that of Sepabeads SP207, positively charged. With respect to the isotherm modeling, as may be seen in Figures 5-8, the best fittings were to the Langmuir-Freundlich model. This is confirmed by $R^{2}$ and $S_{x y}$ values in Table 5, which make evident the differences between fittings to the different isotherm models. 
(a)

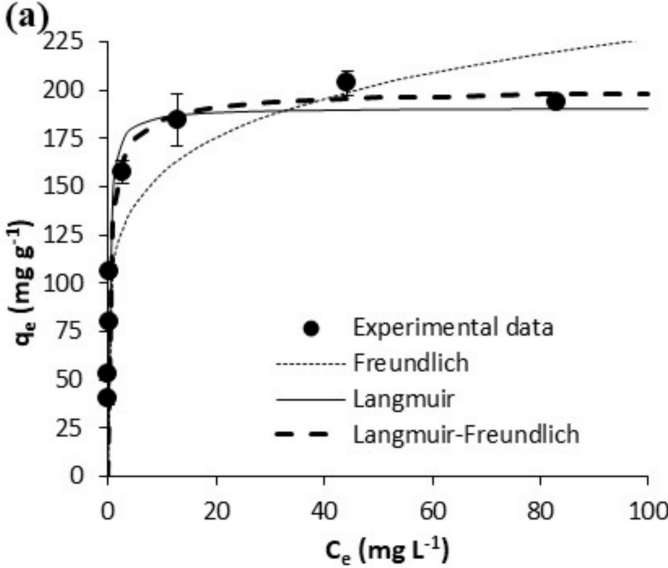

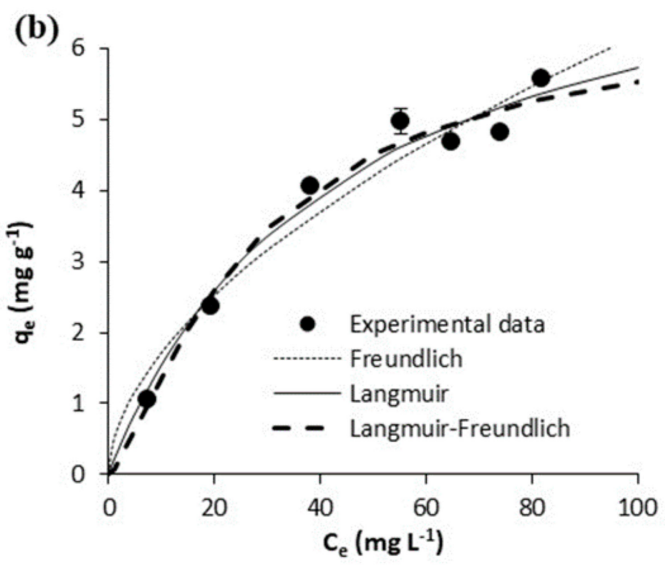

Figure 7. Equilibrium results on the adsorptive removal of acetaminophen from waste water by adsorption onto (a) the activated carbon GPP20 and (b) the polymeric resin Sepabeads SP207. Experimental results are shown together with fittings to the Freundlich, to the Langmuir and to the Langmuir-Freundlich isotherm models. Error bars stand for the standard deviation of three experimental replications. Note: for a better visualization of fittings, the scale of axis $\mathrm{Y}$ has been adjusted to results.
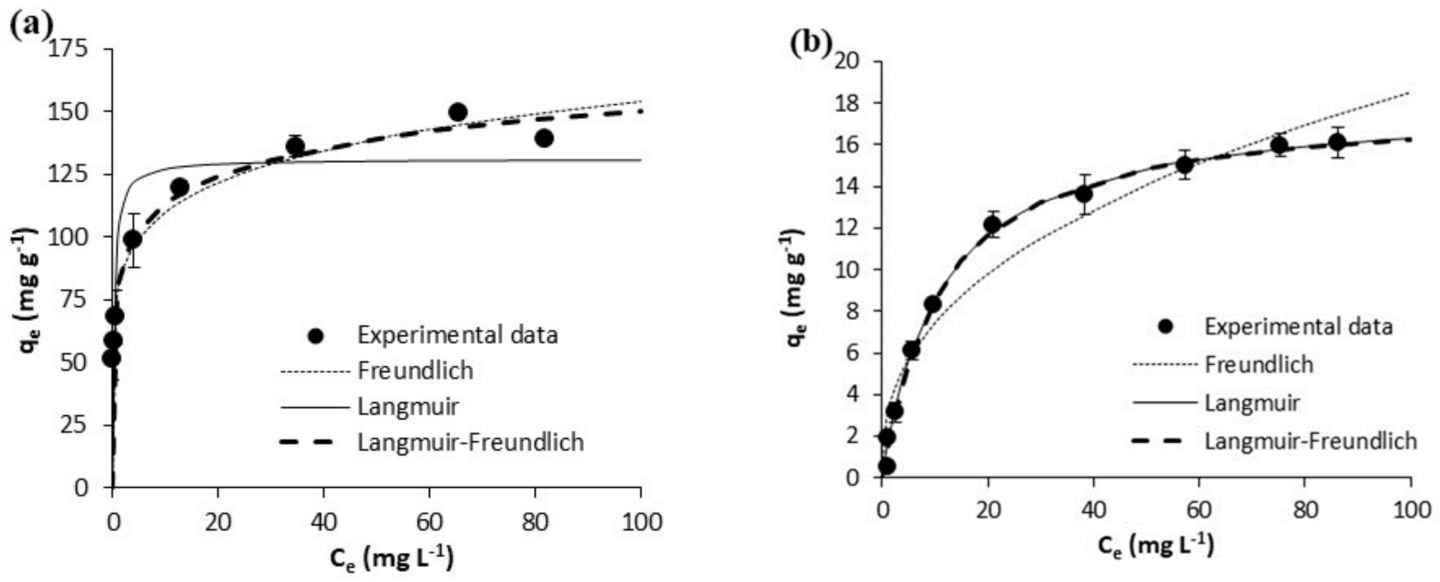

Figure 8. Equilibrium results on the adsorptive removal of ibuprofen from waste water by adsorption onto (a) the activated carbon GPP20 and (b) the polymeric resin Sepabeads SP207. Experimental results are shown together with fittings to the Freundlich, to the Langmuir and to the Langmuir-Freundlich isotherm models. Error bars stand for the standard deviation of three experimental replications. Note: for a better visualization of fittings, the scale of axis $Y$ has been adjusted to results.

As may be seen in Table 5, according to fittings to the Langmuir-Freunlich isotherm, the maximum adsorption capacity $\left(Q_{\mathrm{m}}\right)$ values obtained for acetaminophen onto GPP20 were two orders of magnitude larger than onto Sepabeads SP207. Then, for each adsorbent, equivalent $Q_{\mathrm{m}}$ were obtained for the adsorption of acetaminophen from ultrapure and from waste water. In the case of ibuprofen, the Langmuir-Freundlich fitted $Q_{m}$ values were one order of magnitude larger onto GPP20 than onto Sepabeads SP207. Also, for each adsorbent, similar $Q_{\mathrm{m}}$ were determined for the adsorption of ibuprofen from ultrapure and from waste water. These results are in agreement with those by Suntisukaseam et al. [29], who also found that the adsorption capacity of activated carbon was larger than that of several polymeric resins in the removal of pharmaceuticals (acetaminophen and nalidixic acid) from water. 
According to the fitted Langmuir-Freudnlich isotherms, the average $Q_{\mathrm{m}}$ determined for the adsorption of ibuprofen were larger than for the adsorption of acetaminophen for both of the presently-used adsorbents This is apparently in disagreement with the larger $q_{\mathrm{e}}$ that had been experimentally determined for the adsorption of acetaminophen onto GPP20, as compared with ibuprofen. However, it must be highlighted that large standard deviations were observed for the $Q_{\mathrm{m}}$ values determined for ibuprofen. In fact, although all the isotherms fitted the Langmuir-Freunlich isotherm, those corresponding to the adsorption of acetaminophen onto GPP20 reached a well-defined plateau, which was not the case of ibuprofen. This further supports that, in contrast to ibuprofen, the adsorption of acetaminophen is governed by non-electrostatic interactions.

Regarding the $K_{\mathrm{LF}}$, a parameter that is frequently related to the affinity of the adsorbent for the adsorbate, larger values were determined for GPP20 than for Sepabeads SP207. In the case of GPP20, a larger affinity for acetaminophen than for ibuprofen may be inferred on the basis of $K_{\mathrm{LF}}$ values, which agrees with the neutral charge of GPP20 and acetaminophen at the working pH (both in ultrapure and waste water). Meanwhile, Sepabeads, which is positively charged at the working $\mathrm{pH}$, showed larger affinity for ibuprofen (negative form) than for acetaminophen (neutral).

It is to be noted that, in this work, neither the $q_{\mathrm{e}}$ nor the $Q_{\mathrm{m}}$ values decreased in waste water as compared to ultrapure water, which points to the applicability of both the activated carbon and the polymeric resin for an adsorptive tertiary treatment of waste water.

In the literature, there are published works (ex: $[39,40])$ that report the reduction of the pharmaceuticals adsorption uptake by carbonaceous adsorbents in waste water as compared with ultrapure or distilled water, pointing to the competitive effects of dissolved organic matter (DOM). In contrast, there are studies (ex: [41]) that highlight an increased adsorption capacity of organic pollutants in waste water, and relate this increase to the action of microorganisms in waste water, the adsorbent acting as a bearer surface that favors their degrading. In this sense, Combarros et al. [42] proved that the formation of a bacterial biofilm on the surface of a commercial activated carbon meant the increase of the adsorption of salicylic acid from water. Therefore, in this work, it may be hypothesized the occurrence of a synergism between microorganisms degradation and adsorption for the removal of pharmaceuticals. Thus, the action of microorganisms may have compensated for the competitive effect by DOM so the pharmaceuticals adsorption capacity remained the same in waste water than in ultrapure water.

\section{Conclusions}

Both the polymeric resin Sepabeads SP207 and the activated carbon GPP20 were able to adsorb acetaminophen and ibuprofen from ultrapure and waste water. Adsorption kinetics were faster onto GPP20 than onto Sepabeads SP207, but were mostly unaffected by the aqueous matrix. Experimental results fitted both the pseudo-first and the pseudo-second kinetic models, the latter giving slightly higher correlation coefficients. Equilibrium results onto both the considered adsorbents and for both pharmaceuticals fitted the Langmuir-Freundlich isotherm model, either from ultrapure or from wastewater. The activated carbon displayed larger adsorption capacity values at the equilibrium $\left(202 \mathrm{mg} \mathrm{g}^{-1} \leq Q_{\mathrm{m}} \leq 273 \mathrm{mg} \mathrm{g}^{-1}\right)$ than the polymeric resin $\left(7 \mathrm{mg} \mathrm{g}^{-1} \leq Q_{\mathrm{m}} \leq 18 \mathrm{mg} \mathrm{g}^{-1}\right)$, which was especially remarkable in the case of acetaminophen. Still, the adsorption capacity of these pharmaceuticals onto the employed adsorbents did not decrease in waste water with respect to ultrapure water. This is a very important finding, which points to the practical application of GPP20 and Sepabeads 207 in the tertiary treatment of waste water.

Author Contributions: Conceived and designed the experiments, R.N.C. and M.O.; Software, R.N.C., C.E. and M.O.; Validation, R.N.C. and M.O.; Chemical Analysis, R.N.C. and C.E.; Writing-Review \& Editing, R.N.C., C.E. and M.O.; Supervision, M.O.; Funding Acquisition, M.O.

Funding: This research was funded by the Fundação para a Ciência e a Tecnologia (FCT, Lisboa, Portugal) grant number IF/00314/2015 and by the Ministry of Economy and Competitiveness, State Secretariat for Research, 
Development and Innovation (Madrid, Spain) grant number RYC 2010-05634. C.E. was funded by the Ministry of Educations, Culture and Sports (Madrid, Spain) grant number FPU12/03073.

Acknowledgments: Thanks are due for the financial support to CESAM (UID/AMB/50017) through national funds (Programa de Investimento e Despesas de Desenvolvimento da Administração Central, PIDDAC) by FCT/Ministério da Ciência, Tecnologia e Ensino Superior (MCTES), and through co-funding (POCI-01-0145-FEDER-007638) by the Fundo Europeu de Desenvolvimento Regional (FEDER), within the PT2020 Partnership Agreement and Compete 2020 (Programa Operacional Competitividade e Internacionalização, POCI). Finally, Patricia Quintans, Process and Laboratory Manager at the municipal WWTP of León (Spain), is acknowledged for her friendly assistance.

Conflicts of Interest: The authors declare the inexistence of conflict of interest. Authors also declare that the founding agents did not participate neither decide about the design of the study, the chemical analysis, the interpretation of results, the writing and publishing of the manuscript.

\section{References}

1. Farré, M.; Pérez, S.; Kantiani, L.; Barceló, D. Fate and toxicity of emerging pollutants, their metabolites and transformation products in the aquatic environment. TrAC Trends Anal. Chem. 2008, 27, 991-1007. [CrossRef]

2. Gogoi, A.; Mazumder, P.; Tyagi, V.K.; Tushara, C.; An, A.K.; Kumar, M. Occurrence and fate of emerging contaminants in water environment: A review. Groundw. Sustain. Dev. 2018, 6, 169-180. [CrossRef]

3. Tarpani, R.R.Z.; Azapagic, A. A methodology for estimating concentrations of pharmaceuticals and personal care products (PPCPs) in wastewater treatment plants and in freshwaters. Sci. Total Environ. 2018, 622-623, 1417-1430. [CrossRef] [PubMed]

4. Alfonsín, C.; Hospido, A.; Omil, F.; Moreira, M.T.; Feijoo, G. PPCPs in wastewater-Update and calculation of characterization factors for their inclusion in LCA studies. J. Clean. Prod. 2014, 83, 245-255. [CrossRef]

5. De Andrade, J.R.; Oliveira, M.F.; Da Silva, M.G.C.; Vieira, M.G.A. Adsorption of Pharmaceuticals from Water and Wastewater Using Nonconventional Low-Cost Materials: A Review. Ind. Eng. Chem. Res. 2018, 57, 3103-3127. [CrossRef]

6. Domínguez, J.R.; González, T.; Palo, P.; Cuerda-Correa, E.M. Removal of common pharmaceuticals present in surface waters by Amberlite XAD-7 acrylic-ester-resin: Influence of $\mathrm{pH}$ and presence of other drugs. Desalination 2011, 269, 231-238. [CrossRef]

7. Akhtar, J.; Amin, N.A.S.; Shahzad, K. A review on removal of pharmaceuticals from water by adsorption. Desalin. Water Treat. 2016, 57, 12842-12860. [CrossRef]

8. Mansour, F.; Al-Hindi, M.; Yahfoufi, R.; Ayoub, G.M.; Ahmad, M.N. The use of activated carbon for the removal of pharmaceuticals from aqueous solutions: a review. Rev. Environ. Sci. Bio/Technol. 2018, 17, 109-145. [CrossRef]

9. Coimbra, R.N.; Escapa, C.; Paniagua, S.; Otero, M. Adsorptive removal of diclofenac from ultrapure and wastewater: A comparative assessment on the performance of a polymeric resin and activated carbons. Desalin. Water Treat. 2016, 57, 27914-27923. [CrossRef]

10. Otero, M.; Grande, C.A.; Rodrigues, A.E. Adsorption of salicylic acid onto polymeric adsorbents and activated charcoal. React. Funct. Polym. 2004, 60, 203-213. [CrossRef]

11. Otero, M.; Zabkova, M.; Rodrigues, A.E. Comparative study of the adsorption of phenol and salicylic acid from aqueous solution onto nonionic polymeric resins. Sep. Purif. Technol. 2005, 45, 86-95. [CrossRef]

12. Otero, M.; Zabkova, M.; Rodrigues, A.E. Salicylic acid adsorption onto sephabeads SP206 in view of its purification by thermal parametric pumping. Adsorption 2005, 11, 887-892. [CrossRef]

13. Ramos, A.M.; Otero, M.; Rodrigues, A.E. Recovery of Vitamin B12 and cephalosporin-C from aqueous solutions by adsorption on non-ionic polymeric adsorbents. Sep. Purif. Technol. 2004, 38, 85-98. [CrossRef]

14. Robberson, K.A.; Waghe, A.B.; Sabatini, D.A.; Butler, E.C. Adsorption of the quinolone antibiotic nalidixic acid onto anion-exchange and neutral polymers. Chemosphere 2006, 63, 934-941. [CrossRef] [PubMed]

15. Nilsson, L.; Persson, P.-O.; Rydén, L.; Darozhka, S.; Zaliauskiene, A. Water pollution reduction. In Cleaner Production-Technologies and Tools for Resource Efficient Production; Nilsson, L., Persson, P.-O., Rydén, L., Darozhka, S., Zaliauskiene, A., Eds.; Baltic University Press: Uppsala, Sweden, 2007; p. 129.

16. Lin, G.; Wang, S.; Zhang, L.; Hu, T.; Peng, J.; Cheng, S.; Fu, L. Selective Adsorption of $\mathrm{Ag}^{+}$on a New Cyanuric-Thiosemicarbazide Chelating Resin with High Capacity from Acid Solutions. Polymers 2017, 9, 568. [CrossRef] 
17. Bolong, N.; Ismail, A.F.; Salim, M.R.; Matsuurad, T. A review of the effects of emerging contaminants in wastewater and options for their removal. Desalination 2009, 239, 229-246. [CrossRef]

18. Priac, A.; Morin-Crini, N.; Druart, C.; Gavoille, S; Bradu, C.; Lagarrigue, C.; Torri, G.; Winterton, P.; Crini, G. Alkylphenol and alkylphenol polyethoxylates in water and wastewater: A review of options for their elimination. Arabian J. Chem. 2017, 10, S3749-S3773. [CrossRef]

19. Sophia, A.C.; Lima, E.C. Removal of emerging contaminants from the environment by adsorption. Ecotoxicol. Environ. Saf. 2018, 150, 1-17. [CrossRef] [PubMed]

20. Pereira, A.M.P.T.; Silva, L.J.G.; Laranjeiro, C.S.M.; Meisel, L.M.; Lino, C.M.; Pena, A. Human pharmaceuticals in Portuguese rivers: The impact of water scarcity in the environmental risk. Sci. Total Environ. 2017, 609, 1182-1191. [CrossRef] [PubMed]

21. Lin, H.; Li, H.; Chen, L.; Li, L.; Yin, L.; Lee, H.; Yang, Z. Mass loading and emission of thirty-seven pharmaceuticals in a typical municipal wastewater treatment plant in Hunan Province, Southern China. Ecotoxicol. Environ. Saf. 2018, 147, 530-536. [CrossRef] [PubMed]

22. Bellver-Domingo, A.; Fuentes, R.; Hernández-Sancho, F. Shadow prices of emerging pollutants in wastewater treatment plants: Quantification of environmental externalities. J. Environ. Manag. 2017, 203, $439-447$. [CrossRef] [PubMed]

23. Escapa, C.; Coimbra, R.N.; Nuevo, C.; Vega, S.; Paniagua, S.; García, A.I.; Calvo, L.F.; Otero, M. Valorization of microalgae biomass by its use for the removal of paracetamol from contaminated water. Water 2017, 9, 312. [CrossRef]

24. Lessa, E.F.; Nunes, M.L.; Fajardo, A.R. Chitosan/waste coffee-grounds composite: An efficient and eco-friendly adsorbent for removal of pharmaceutical contaminants from water. Carbohydr. Polym. 2018, 189, 257-266. [CrossRef] [PubMed]

25. Sumalinog, D.A.G.; Capareda, S.C.; de Luna, M.D.G. Evaluation of the effectiveness and mechanisms of acetaminophen and methylene blue dye adsorption on activated biochar derived from municipal solid wastes. J. Environ. Manag. 2018, 210, 255-262. [CrossRef] [PubMed]

26. An, H.J.; Bhadra, B.N.; Khan, N.A.; Jhung, S.H. Adsorptive removal of wide range of pharmaceutical and personal care products from water by using metal azolate framework-6-derived porous carbon. Chem. Eng. J. 2018, 343, 447-454. [CrossRef]

27. Ondarts, M.; Reinert, L.; Guittonneau, S.; Baupc, S.; Delpeux, S.; Lévêque, J.-M.; Duclaux, L. Improving the adsorption kinetics of ibuprofen on an activated carbon fabric through ultrasound irradiation: Simulation and experimental studies. Chem. Eng. J. 2018, 343, 163-172. [CrossRef]

28. Verma, V.K.; Subbiah, S. Prospects of Silk Sericin as an Adsorbent for Removal of Ibuprofen from Aqueous Solution. Ind. Eng. Chem. Res. 2017, 56, 10142-10154. [CrossRef]

29. Suntisukaseam, U.; Weschayanwiwat, P.; Sabatini, D.A. Sorption of amphiphile pharmaceutical compounds onto polar and nonpolar adsorbents. Environ. Eng. Sci. 2007, 24, 1457-1465. [CrossRef]

30. Silva, C.P.; Jaria, G.; Otero, M.; Esteves, V.I.; Calisto, V. Waste-based alternative adsorbents for the remediation of pharmaceutical contaminated waters: Has a step forward already been taken? Bioresour. Technol. 2018, 250, 888-901. [CrossRef] [PubMed]

31. Kårelid, V.; Larsson, G.; Björlenius, B. Pilot-scale removal of pharmaceuticals in municipal wastewater: Comparison of granular and powdered activated carbon treatment at three wastewater treatment plants. J. Environ. Manag. 2017, 193, 491-502. [CrossRef] [PubMed]

32. Wang, X.; Hansen, C.; Allen, K. Extraction of anthocyanins from black bean canning wastewater with macroporous resins. J. Food Sci. 2014, 79, E184-E188. [CrossRef] [PubMed]

33. APHA-AWWA-WPCF. Standard Methods for the Examination of Water and Wastewater, 20th ed.; American Public Health Association: Washington, DC, USA, 2001.

34. Lagergren, S. Zur theorie der sogenannten adsorption gelöster stoffe. K. Sven. Vetenskapsakad. Hand. 1898, 24, $1-39$.

35. Ho, Y.S.; McKay, G. Pseudo-second order model for sorption processes. Process Biochem. 1999, 34, 451-465. [CrossRef]

36. Freundlich, H. Über die Adsorption in Lösungen. Z. Phys. Chem. 1906, 57, 385-470. [CrossRef]

37. Langmuir, I. The Adsorption of Gases on Plane Surfaces of Glass, Mica and Platinum. J. Am. Chem. Soc. 1918, 40, 1361-1403. [CrossRef]

38. Sips, R. Combined form of Langmuir and Freundlich equations. J. Chem. Phys. 1948, 16, 490-495. [CrossRef] 
39. Sotelo, J.L.; Rodríguez, A.R.; Mateos, M.M.; Hernández, S.D.; Torrellas, S.A.; Rodríguez, J.G. Adsorption of pharmaceutical compounds and an endocrine disruptor from aqueous solutions by carbon materials. J. Environ. Sci. Health Part B 2012, 47, 640-652. [CrossRef] [PubMed]

40. Kovalova, L.; Knappe, D.R.U.; Lehnberg, K.; Kazner, C.; Hollender, J. Removal of highly polar micropollutants from wastewater by powder activated carbon. Environ. Sci. Pollut. Res. 2013, 20, 3607-3615. [CrossRef] [PubMed]

41. Méndez-Díaz, J.D.; Abdel daiem, M.M.; Rivera-Utrilla, J.; Sánchez-Polo, M.; Bautista-Toledo, I. Adsorption/bioadsorption of phthalic acid, an organic micropollutant present in landfill leachates, on activated carbons. J. Colloid Interface Sci. 2012, 369, 358-365. [CrossRef] [PubMed]

42. Combarros, R.G.; Rosas, I.; Lavín, A.G.; Rendueles, M.; Díaz, M. Influence of biofilm on activated carbon on the adsorption and biodegradation of salicylic acid in wastewater. Water Air Soil Pollut. 2014, 225, 1858. [CrossRef]

(C) 2018 by the authors. Licensee MDPI, Basel, Switzerland. This article is an open access article distributed under the terms and conditions of the Creative Commons Attribution (CC BY) license (http://creativecommons.org/licenses/by/4.0/). 